Original Article

\title{
Antioxidant and flavor properties of Angelica sinensis extracts as affected by processing
}

\author{
Shih-Hao Huang ${ }^{\mathrm{a}, \mathrm{d}}$, Chien-Chung Chen ${ }^{\mathrm{b}}$, Chun-Mao Lin ${ }^{\mathrm{c}}$, Been-Huang Chiang ${ }^{\mathrm{a}, *}$ \\ a Institute of Food Science and Technology, National Taiwan University, Taipei, Taiwan \\ ${ }^{\mathrm{b}}$ Department of Tourism, Shih Hsin University, Taipei, Taiwan \\ c College of Medicine, Taipei Medical University, Taipei, Taiwan \\ ${ }^{\mathrm{d}}$ Department of Food Science, Taipei College of Maritime Technology, Taipei, Taiwan
}

\section{A R T I C L E I N F O}

\section{Article history:}

Received 14 January 2007

Received in revised form

10 October 2007

Accepted 11 February 2008

\section{Keywords:}

Angelica sinensis

Dong-gui: Chinese herbal medicine

Chinese nutraceutical: antioxidant activity

Ferulic acid

Lipid peroxidation

DNA relaxation

Volatile compounds

Nitric oxide

Food composition

Food analysis

\begin{abstract}
A B S T R A C T
Angelica sinensis (AS) was extracted with water or $20 \%$ ethanol for different time periods, and the antioxidant activity as well as flavor quality of the extracts were investigated. The AS extracts contained significant amount of phenolic acids, including nicotinic acid, phthalic acid, $p$-coumaric acid, and ferulic acid. Regardless the water or alcohol extraction, most of the phenolic acids reached their maximum values in $15 \mathrm{~min}$. Assays including inhibition of 1,1-diphenylpicrylhydrazyl (DPPH), lipid peroxidation, and DNA relaxation activities also indicated that $15 \mathrm{~min}$ extraction resulted in a product with the highest antioxidant activity. The 15 min AS extracts in the concentration range of $20-200 \mu \mathrm{g} / \mathrm{ml}$ also showed inhibitory effects on NO production in LPS-activated RAW 264.7 macrophage in a dosedependent manner. Statistical analysis revealed that the antioxidant activity and phenolic acid concentration for all AS extracts exhibited a positive and significant linear correlation, suggesting that the phenolic acids are the important contributors for the antioxidant activity of the AS extracts. The contents of volatile compounds of AS were much higher in the $20 \%$ ethanol extracts than those in water extracts. In the $20 \%$ ethanol extracts, the amount of ligustilide, butylidene phthalide and butyl phthalide were higher in the 30-min extracts than that prepared for longer time. Considering both of antioxidant activity and flavor quality, the AS extract should be prepared with $20 \%$ ethanol with extraction time less than 30 min.
\end{abstract}

(c) 2008 Elsevier Inc. All rights reserved.

\section{Introduction}

The rhizome of Angelica sinensis (Oliv.) Diels (Umbelliferae), known as Dong-gui in Chinese herb, is one of the most important traditional Chinese herbs used as a sedative or a tonic agent (Hsu and Peacher, 1976). Its varieties of pharmacological effects include anti-oxidative, anti-inflammatory, and immunomodulatory activities (Wu et al., 1999; Liu et al., 2003). The active components of Angelica sinensis (AS) include ferulic acid and polysaccharides, the main components found in the non-aromatic fractions. The ligustilide and phthalides are found in the volatile aromatic oil.

Ferulic acid (4-hydroxy-3-methoxycinnamic acid), a phenolic compound, has antioxidant and anti-inflammatory activities and chemopreventive effect on carcinogenesis (Lu et al., 2005; Ou and Kwok, 2004). Ferulic acid has been demonstrated to protect against free radical-mediated changes in conformation with synaptosomal membrane proteins (Kanski et al., 2002). Long-term

\footnotetext{
* Corresponding author. Tel.: +8862 33664119; fax: +886223620849.

E-mail address: bhchiang@ntu.edu.tw (B.-H. Chiang).
}

oral administration of ferulic acid significantly reduced $A \beta_{1-42^{-}}$ induced memory impairment in mice (Yan et al., 2001). Ligustilide is a volatile and unstable compound, which can change to other phthalides through oxidation and dimerization (Lu et al., 2004; Doneanu and Anitescu, 1998; Song et al., 2004). Ligustilide and butylidene phthalide possess the suppressive and modulatory activities to the central nervous system (Matsumoto et al., 1998). ROS are capable of causing lipid peroxidation, the oxidation of amino acid residues, the formation of protein-protein cross-links, and DNA oxidative damage. Under normal physiological conditions, ROS can be scavenged by the cellular defending systems, but under certain pathological conditions, the dynamic balance between the generation and elimination of ROS may be broken, causing increases in cellular ROS levels. High levels of ROS may do oxidative damage to various cellular components, and result in cell death. It is believed that ROS are associated with various diseases such as cancer, arteriosclerosis, diabetes, and Alzheimer's disease (Khan, 2002; Johar et al., 2004; Varadarajan et al., 2000; Markesbery, 1997).

ROS can also function as signaling molecules and inducers of signaling pathways in many cell types (Lander et al., 1996). 
Increases in oxidative stress may promote inflammatory cytokine production by the activation of redox-sensitive signal transduction pathways such as the mitogen-activated protein kinase (MAPK) and NF- $\kappa B$ (Suzuki et al., 1997). These signaling pathways control the expression of many genes involved in the innate inflammatory response, cellular proliferation, and apoptosis (Tse et al., 2004). Nitric oxide production has been implicated in the process of carcinogenesis and inflammation. Excessive iNOS (inducible nitric oxide synthase)-mediated NO generation has been reported to cause mutagenesis and deamination of DNA bases and to form carcinogenic $N$-nitrosoamine (Huang et al., 2005). Antioxidant, such as docosahexaenoic acid, has been proven to be able to inhibit the accumulation of intracellular peroxides, and indirectly result in the inhibition of NO production and iNOS expression (Komatsu et al., 2003). And inhibitors of iNOS may have a therapeutic role in certain cancers (Lala and Chakraborty, 2001).

Because of the health-promoting function and its unique pleasant flavor, Angelica sinensis is frequently used as an ingredient for preparing medicinal Chinese foods, such as Donggui Duck, Dong-gui Chicken, and Dong-gui Mutton. Traditionally, the Dong-gui foods is often prepared by mixing these food materials with slices of Dong-gui, covering with water or rice wine (containing alcohol 20\%), and simmering for several hours. It is assumed that longer cooking time would extract more active components from AS. However, some of the active compounds may decompose during the long processing time involving high heat (Lu et al., 2004; Song et al., 2004; Gadow et al., 1997). Many antioxidants in foods are significantly lost as a consequence of processes such as sterilization, pasteurization, and dehydration as well as prolonged storage (Manzocco et al., 1998). Long-term cooking may also cause the loss of volatile compounds and affect the flavor quality of the foods. Therefore, this study was carried out to investigate the changes of non-volatile components and their effects on the antioxidant activity of AS extracts. In addition, the changes of volatile components were monitored in order to evaluate the effect of extraction at elevated temperatures on the flavor property of $A$. Sinensis.

\section{Materials and methods}

\subsection{Chemicals and materials}

LPS (Escherichia coli 0127:B8) and other chemicals were from Sigma chemical Co. (St. Louis, MO). All of the solvents used in this study were from E. Merck (Darmstadt, Germany). The DMEM medium, fetal bovine serum, penicillin, and streptomycin were obtained from Gibco BRL (Grand Island, NY). A. Sinensis (Oliv.) Diels (AS) were purchased from a Chinese medicine shop (Jung-hwa, Taipei, Taiwan).

\subsection{Preparation of $A$. sinensis extracts}

A. sinensis (AS) was identified by the Center of Herbal Authentication of Taipei Medical University and stored at $-20^{\circ} \mathrm{C}$ To simulate the preparation of medicinal Chinese foods, $40 \mathrm{~g}$ of sliced AS was extracted in 21 of boiling water, and another $40 \mathrm{~g}$ were extracted using 21 of $20 \%$ boiling ethanol solution for various periods of time $(15,30,60,90 \mathrm{~min})$. The extract was cooled and centrifuged at $5000 \mathrm{rpm}$ for $10 \mathrm{~min}$, and filtered to remove insoluble materials. The supernatants were adjusted to the original volume (21), and the obtained preparations were designated ASW (A. sinensis water extractions) and ASalc (A. sinensis alcohol extractions) and stored at $-20^{\circ} \mathrm{C}$.

\subsection{Determination of phenolic acids}

The phenolic acids were analyzed by HPLC (Agilent 1100 HPLC system, Palo Alto, CA) equipped with a diode-array detector (DAD). The separations were performed on a HS ODS column $\left(5 \mu \mathrm{m}, 250 \times 4.6 \mathrm{~mm}\right.$, Torrance, CA) at $25^{\circ} \mathrm{C}$. Aliquots of $20-\mu \mathrm{L}$ were injected and eluted at flow rate $0.8 \mathrm{~mL} / \mathrm{min}$ with a mobile phase composed of solution A ( $30 \mathrm{mM}$ potassium dihydrogen phosphate at $\mathrm{pH} 3.50$ ) and solution $\mathrm{B}$ (acetonitrile $/ \mathrm{H}_{2} \mathrm{O}=80 / 20$ ). Phenolic compounds in the AS extracts were eluted with gradient from $100 \%$ A initially to $90 \% \mathrm{~A}$ and $10 \% \mathrm{~B}$ at $20 \mathrm{~min}, 88 \% \mathrm{~A}$ and $12 \%$ $\mathrm{B}$ at $30 \mathrm{~min}, 35 \mathrm{~min}, 70 \% \mathrm{~A}$ and $30 \% \mathrm{~B}, 40 \% \mathrm{~A}$ and $60 \% \mathrm{~B}$ at $45 \mathrm{~min}$, and $100 \% \mathrm{~B}$ at $50 \mathrm{~min}$. Detection was at $320 \mathrm{~nm}$ for ferulic acid and $210 \mathrm{~nm}$ for other phenolic acids. The limit of detection (LOD) has been estimated as $3 \mathrm{SD}$. The total peak area of phenolic acids (TPA) was also used for determining the total phenolic acids content, which is defined as the sum of peaks area $\geqq 3$ SD. For the calibration of phenolic acids, the standards were weighed and dissolved in methanol to give serial concentrations and three injections onto HPLC were performed for each dilution. The concentrations of phenolic acids in the samples were calculated according to the standard curve. The results were expressed as microgram per milliliter of AS extracts.

\subsection{Quantification of volatile compounds}

The liquid-liquid extraction method was used to extract the volatile compounds of AS extracts (Charles et al., 2000). An aliquot of $100 \mathrm{~mL}$ AS extracts, $200 \mathrm{~mL}$ dichloromethane, and $10 \mathrm{mg} / \mathrm{L}$ $n$-decanol as internal standard, was mixed in a flask cooled by crushed ice for $30 \mathrm{~min}$. After settling for ca. $30 \mathrm{~min}$, the bottom layer (dichloromethane) was collected using a separator funnel. The dichloromethane extracts were dried over anhydrous sodium sulfate, and concentrated by a vacuum evaporator at $30^{\circ} \mathrm{C}$ and $30 \mathrm{~cm}-\mathrm{Hg}$ vacuum. Then, the residue was re-dissolved in methanol, filtered with $0.22 \mu \mathrm{M}$ PVDF, and stored at $-80^{\circ} \mathrm{C}$ for analysis. Volatile compounds were identified and quantified by GC-MS (Doneanu and Anitescu, 1998) using a Hewlett-Packard 5890 Series II chromatograph coupled to a Hewlett-Packard 5890A MSD mass spectrometer, and equipped with Carbowax $20 \mathrm{M}$ column $(30 \mathrm{~m} \times 0.32 \mathrm{~mm}$ i.d., film thickness $=0.25 \mu \mathrm{M})(\mathrm{J} \& \mathrm{~W}$ Scientific Inc., Folsom, CA, USA). The injector temperature was $220^{\circ} \mathrm{C}$, detector temperature $260^{\circ} \mathrm{C}$, and the oven programmed from 50 to $220^{\circ} \mathrm{C}$ at an increasing rate of $5^{\circ} \mathrm{C} / \mathrm{min}$. The carrier gas was helium at a flux of $0.8 \mathrm{~mL} / \mathrm{min}$. Compounds were identified by the comparison of GC-MS spectra to their characteristic spectra from a database. Ligustilide, butyl phthalide, and butylidene phthalide were determined on the basis of the internal standard. The results were expressed as milligram per $100 \mathrm{~mL}$ of AS extracts.

\subsection{Antioxidant activities of AS extracts}

\subsubsection{DPPH radical scavenging assay}

The reaction was performed in $3 \mathrm{~mL}$ of methanol containing $250 \mu \mathrm{M}$ of freshly prepared 1,1-diphenylpicrylhydrazyl (DPPH) and $1 \mathrm{~mL}$ of the AS extracts. Reaction mixtures were protected from light and incubated for $90 \mathrm{~min}$ at room temperature, after which the absorbance of the remaining DPPH was determined colorimetrically at $517 \mathrm{~nm}$. The scavenging activity of AS extracts were measured as the decrease in absorbance of the DPPH expressed as a percentage of the absorbance of a control DPPH solution without AS extracts (Chen et al., 2000). All analyses were carried out in triplicate. 


\subsubsection{Inhibition of lipid peroxidation}

Lipid peroxidation was assayed by measuring malondialdehyde (MDA) according to the method of Sánchez-Moreno et al. (1999). Arachidonic acid was oxidized by the Fenton reaction $\left(\mathrm{Fe}^{2+} / \mathrm{H}_{2} \mathrm{O}_{2}\right)$. The AS extracts were added to $0.5 \mathrm{~mL}$ of an aqueous solution containing arachidonic acid $(2.5 \mathrm{mM}), 0.25 \mathrm{mmol}$ of Trizma-HCl/0.75 mmol of potassium chloride buffer ( $\mathrm{pH} 7.4$ ), $0.2 \% \mathrm{~N}$-lauroyl sarcosine, $1 \mu \mathrm{M}$ of ferrous sulfate, and $0.5 \mu \mathrm{M}$ of hydrogen peroxide in a $2 \mathrm{~mL}$ micro-tube. The mixture was agitated for $16 \mathrm{~h}$ at $37^{\circ} \mathrm{C}$ The degree of oxidation was measured by the thiobarbituric acid method. An aliquot of $20 \mu \mathrm{L}$ testing solution was mixed in a microtube with $20 \mu \mathrm{L}$ aqueous $8 \%$ sodium dodecyl sulfate (SDS) $150 \mu \mathrm{L}$ of $1 \mathrm{M}$ acetate buffer, and $150 \mu \mathrm{L}$ of aqueous $0.67 \%$ 2-Thiobarbituric acid (TBA). The mixture was heated at $90^{\circ} \mathrm{C}$ for $60 \mathrm{~min}$. After cooling, $0.5 \mathrm{~mL}$ of butanol was added and mixed. The solution was centrifuged, and the absorbance of the upper butanol layer was measured at $532 \mathrm{~nm}$. The antioxidant activity of the tested sample for lipid peroxidation was expressed by the \% inhibition, which was calculated as: \% inhibition $=[($ absorbance of control-absorbance of test sample $)]$ absorbance of control] $\times 100 \%$. A test solution without AS extracts was used as control.

\subsubsection{Inhibition of plasmid DNA relaxation}

The inhibitory effect of AS extracts on super-coiled DNA strand breakage nicking caused by the Fenton reaction was evaluated (Ermilov et al., 1999). An amount of $200 \mathrm{ng}$ of pUC-19 plasmid DNA was incubated at $37{ }^{\circ} \mathrm{C}$ for $30 \mathrm{~min}$ in TE buffer $(10 \mu \mathrm{M}$ Tris/ $1 \mu \mathrm{M}$ EDTA, $\mathrm{pH}=8.0$ ) containing $100 \mathrm{mM}$ hydrogen peroxide and $100 \mu \mathrm{M}$ ferrous sulfate. This was done in the presence or absence of AS extracts with a final volume of $20 \mu \mathrm{L}$. Then, the samples were loaded onto $1 \%$ agarose gel, and electrophoresis was performed in a TAE buffer $(40 \mathrm{mM}$ of Tris-acetate and $1 \mathrm{mM}$ of EDTA) in the presence of $0.5 \mu \mathrm{g} / \mathrm{mL}$ of ethidium bromide. After electrophoresis, the gel was photographed under transmitted ultraviolet light.

\subsection{Nitric oxide (NO) assay}

\subsubsection{Cell culture}

The mouse monocyte-macrophage cell line RAW 264.7 (ATCC TIB-71) was cultured in Dulbecco's modified Eagle's (DMEM) medium supplemented with $10 \%$ heat-inactivated fetal bovine serum. Cells were plated in at a density of $1.0 \times 10^{6} \mathrm{~mL}^{-1}$ for $18-24 \mathrm{~h}$ before activation by lipopolysaccharide (LPS) $(50 \mathrm{ng} / \mathrm{mL})$. AS extracts dissolved in the DMEM medium were administered with LPS.

\subsubsection{Determination of nitrite}

The nitrite accumulating in the culture medium was measured as an indicator of NO production according to the Griess reaction (Kim et al., 1995). Cells were plated in 24-well culture plate and stimulated with LPS $(50 \mathrm{ng} / \mathrm{mL})$ in the presence or absence of various concentrations of AS extracts for $24 \mathrm{~h}$. An aliquot of $100 \mu \mathrm{L}$ of the culture medium (cell free) was mixed with $50 \mu \mathrm{L} 1 \%$ sulfanilamide (in $5 \%$ phosphoric acid) and $50 \mu \mathrm{L} 0.1 \%$ naphthylethylenediamine dihydrochloride (in distilled $\mathrm{H}_{2} \mathrm{O}$ ) at room temperature. Absorbance at $550 \mathrm{~nm}$ was measured with a sodium nitrite serial dilution standard curve, and nitrite production was determined.

\subsection{Statistical analysis}

The results were represented as the means \pm standard deviation from three independent experiments $(n=3)$. Statistical analysis was performed using ANOVA. The difference between the means was determined by Duncan's multiple range test.

\section{Results and discussion}

\subsection{Non-volatile components of AS extracts}

The amounts of phenolic acids from AS subjected to different extraction conditions were examined because these non-volatile compounds are considered to be the biologically active components of AS (Graf, 1992; Huang and Sheu, 2006). Fig. 1 shows the chemical structure of phenolic acids, a major class of phenolic compounds that occur widely in the plant kingdom (Proestos et al., 2006). Predominant phenolic acids include hydroxybenzoic acids (e.g. protocatechuic acid, vanillic acid) and hydroxycinnamic acids (e.g. ferulic acid, caffeic acid, $p$-coumaric acid, cinnamic acid). Although the nicotinic acid does not belong to the family of phenolic acids, it is an important chemical constituents of A. sinensis (Hsu, 1968; Huang and Sheu, 2006). The phenolic compounds were readily identified using HPLC-DAD by comparison with authentic standards. Fig. 2 displays a typical HPLC chromatogram of phenolic standards. The HPLC profiles in Fig. 2B show that AS extract (20\% ethanol extraction) contained significant amount of nicotinic acid, phthalic acid, $p$-coumaric acid, and ferulic acid.

The effects of extraction time and types of solvent on the phenolic acid contents of AS extracts are shown in Table 1 . The ferulic acid contents were the highest among various phenolic acids in AS extracts. Cai et al. (2004) summarized the major types of phenolic acids from most medicinal herbs, and indicated that ferulic acid was the major phenolic compound in AS. In the water extraction, most of the phenolic acids reached their maximum values in $15 \mathrm{~min}$ except the ferulic acid content reached a high point in $30-60 \mathrm{~min}(18.9 \mu \mathrm{g} / \mathrm{mL})$, and decreased once the time surpassed $60 \mathrm{~min}$. In the $20 \%$ ethanol extraction, the ferulic acid, nicotinic acid, $p$-coumaric acid, and phthalic acid contents all displayed the highest value within $15 \mathrm{~min}$. It should be noted that the contents of phenolic acids in the ethanol extracts decreased after $15 \mathrm{~min}$ of extraction, but increased again when the extraction time extended to $90 \mathrm{~min}$. There are several possibilities. First, some of the phenolics might be destructed during thermal processing. Second, the major phenolic compound, ferulic acid, is readily oxidized under heat, and therefore could be degraded due to the boiling (Song et al., 2004; Zhao et al., 2003). Third, it has been found that beside the natural content of ferulic acid in herbs, the free ferulic acid could be obtained during processing through hydrolyzing compounds such as coniferyl ferulate (Lu et al., 2005). It was therefore suspected that changes of phenolic acids contents in the AS extracts were most likely affected by the combined effects of the phenomena described above. Nevertheless, it appeared that $15 \mathrm{~min}$, in general, was enough to extract most of the phenolic acids from the AS, and the 20\% ethanol solution might be the preferred solvent.

Because of the diversity and complexity of the natural mixtures of phenolic compounds in AS extracts, characterizing every compound is rather difficult. In this study, the total peak area of phenolic acids (TPA) as determined by HPLC was also used for determining the total phenolic acids content in the extract (Table 1). It appeared that $15 \mathrm{~min}$, in general, was enough to extract most of the phenolic acids from the AS.

\subsection{Antioxidant activity of $A$. sinensis extracts}

The inhibition of 1,1-diphenylpicrylhydrazyl (DPPH), lipid peroxidation, and DNA relaxation activities by various AS extracts 
<smiles>O=C(O)c1cccnc1</smiles>

Nicotinic acid<smiles>[R]c1cc([R1])c(C(=O)O)cc1[R]</smiles>

Phthalic acid, R1=R2=H, R3=COOH

Protocatechuic acid, R1=R2=OH, R3=H

Vanillic acid, R1=OMe, R2=OH, R3=H<smiles>[R2]c1ccc(/C=C/C(=O)O)cc1[R2]</smiles>

Caffeic acid, R1=R2=OH

Ferulic acid, R1=OMe, R2=OH

p-coumaric acid, R1=H, R2=OH

trans-cinnamic acid, R1=R2=H

Fig. 1. Chemical structures of phenolic acids and nicotinic acid.

A

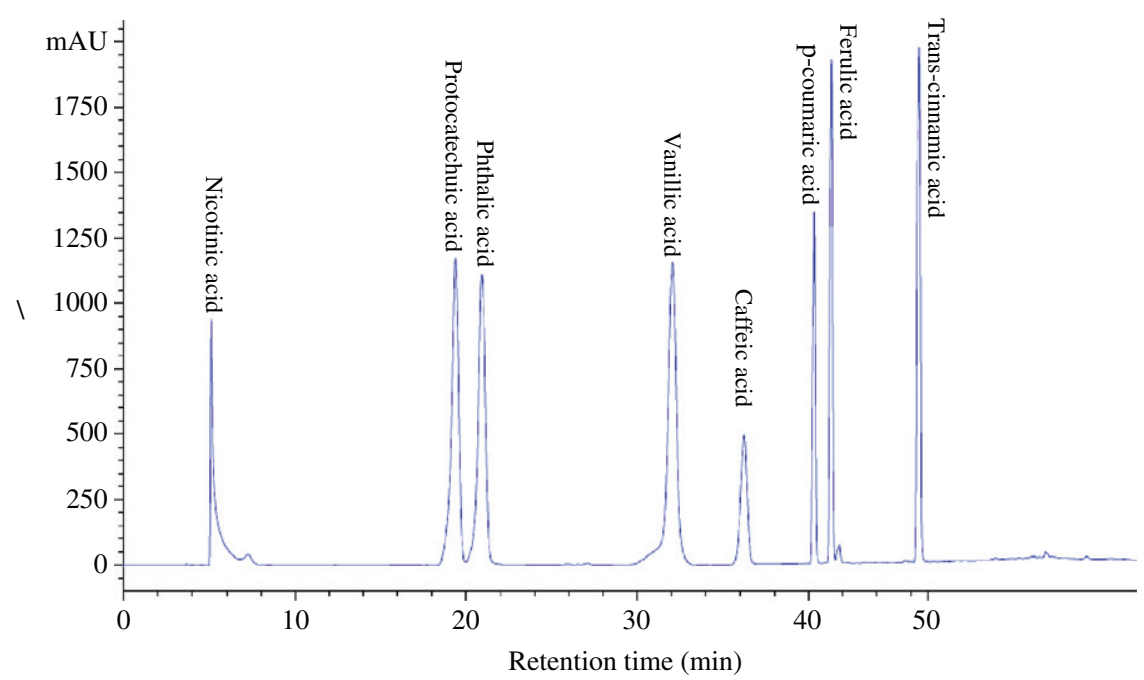

B

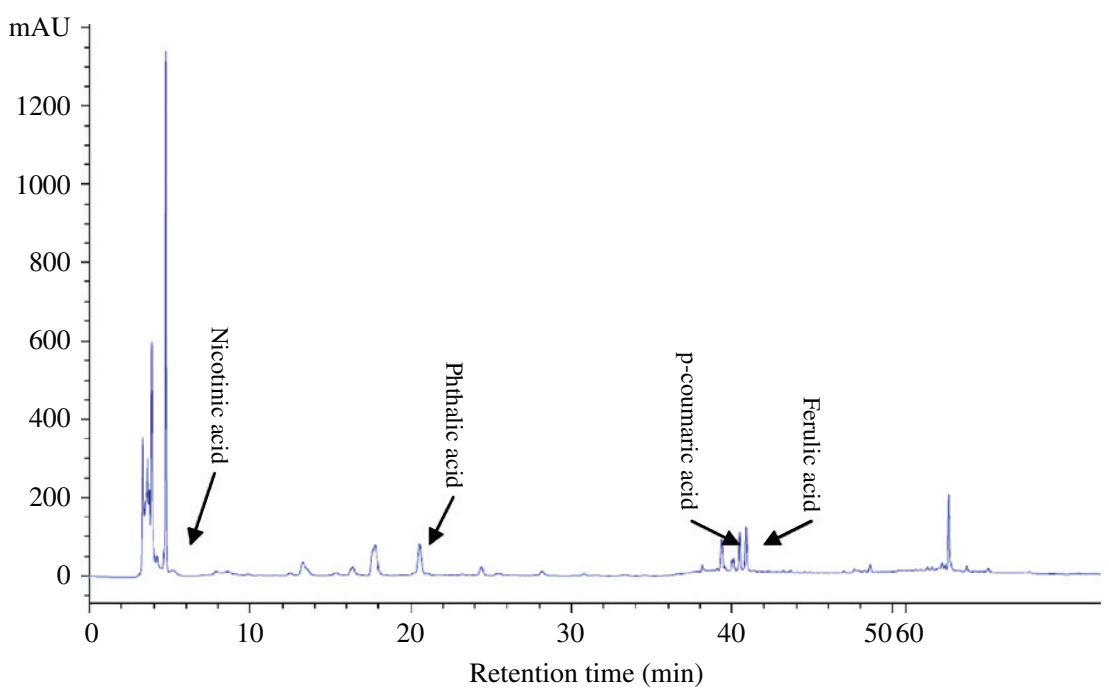

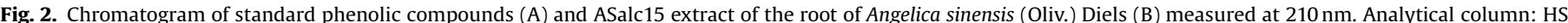

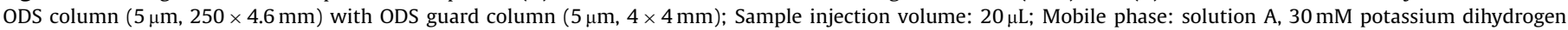
phosphate, $\mathrm{pH}=3.5$, and solution $\mathrm{B}$, acetonitrile $/ \mathrm{H}_{2} \mathrm{O}=80 / 20$, flow rate: $0.8 \mathrm{~mL} / \mathrm{min}$; temperature: ambient.

were assessed for their antioxidant activity. DPPH radicals were routinely used for evaluating the antioxidant activity of plants, red wine, and tea extracts. The DPPH scavenging activities were not significantly different among 15-, 30-, and 90-min AS water extracts (ASW), but the 15- and 60-min water extracts (ASW15 and ASW60) showed a higher scavenging effect (Table 2). For the ethanol extracts (ASalc), the highest scavenging activity appeared at $15 \mathrm{~min}$, and decreased as the extraction time was prolonged. 
Table 1

Phenolic acid contents of Angelica sinensis with different extraction conditions

\begin{tabular}{|c|c|c|c|c|c|}
\hline Treatment of AS & Nicotinic acid $(\mu \mathrm{g} / \mathrm{mL})$ & Phthalic acid $(\mu \mathrm{g} / \mathrm{mL})$ & P-coumaric acid $(\mu \mathrm{g} / \mathrm{mL})$ & Ferulic acid $(\mathrm{Mg} / \mathrm{mL})$ & TPA (mAUs) \\
\hline ASW15 & $2.46 \pm 0.64 \mathrm{a}$ & $0.44 \pm 0.03 a b$ & $1.49 \pm 0.24 \mathrm{a}$ & $15.8 \pm 1.7 \mathrm{bc}$ & $25378 \pm 1408 \mathrm{ab}$ \\
\hline ASW30 & $2.23 \pm 0.66 \mathrm{a}$ & $0.51 \pm 0.03 \mathrm{a}$ & $1.59 \pm 0.16 \mathrm{a}$ & $16.7 \pm 2.0 \mathrm{ab}$ & $25552 \pm 2457 \mathrm{ab}$ \\
\hline ASW60 & $1.91 \pm 0.07 \mathrm{ab}$ & $0.43 \pm 0.02 a b$ & $1.84 \pm 0.33 \mathrm{a}$ & $18.9 \pm 2.7 \mathrm{a}$ & $27133 \pm 3571 a b$ \\
\hline ASW90 & $1.69 \pm 0.21 \mathrm{ab}$ & $0.38 \pm 0.1 \mathrm{~b}$ & $1.64 \pm 0.85 \mathrm{a}$ & $15.1 \pm 1.2 \mathrm{bc}$ & $23913 \pm 3649 b$ \\
\hline ASalc15 & $2.14 \pm 0.18 \mathrm{a}$ & $0.44 \pm 0.03 \mathrm{ab}$ & $1.68 \pm 0.35 a$ & $17.1 \pm 1.5 \mathrm{ab}$ & $29489 \pm 2551 a$ \\
\hline ASalc30 & $2.27 \pm 0.39 \mathrm{a}$ & $0.41 \pm 0.07 \mathrm{ab}$ & $1.51 \pm 0.51 \mathrm{a}$ & $15.6 \pm 3.0 \mathrm{bc}$ & $23700 \pm 3942 b$ \\
\hline ASalc60 & $1.30 \pm 0.10 \mathrm{~b}$ & $0.21 \pm 0.01 \mathrm{c}$ & $1.03 \pm 0.56 \mathrm{a}$ & $13.9 \pm 4.1 \mathrm{c}$ & $16985 \pm 5934 \mathrm{c}$ \\
\hline ASalc90 & $1.70 \pm 0.48 \mathrm{ab}$ & $0.43 \pm 0.11 \mathrm{ab}$ & $1.31 \pm 0.86 \mathrm{a}$ & $15.8 \pm 1.9$ bc & $25261 \pm 2211 a b$ \\
\hline
\end{tabular}

ASW represents water extraction.

ASalc represents alcohol extraction.

Mean \pm SD $(n=3)$, mean within a column followed by the same lowercase letter are not significantly different at $p>0.05$.

The total peaks area of phenolic acids (TPA): the sum of phenolic acids peak areas $\geqq 3$ SD.

Table 2

Comparison of DPPH free radical scavenging activities and lipid peroxidation inhibitory activities of $A$. sinensis extracts

\begin{tabular}{lll}
\hline Treatment of AS & $\begin{array}{l}\text { DPPH scavenging } \\
\text { activity (\% of control) }\end{array}$ & $\begin{array}{l}\text { Lipid peroxidation } \\
\text { inhibitory activity } \\
\text { (\% of control) }\end{array}$ \\
\hline ASW15 & $75.7 \pm 1.6 \mathrm{abc}$ & $85.1 \pm 4.4 \mathrm{a}$ \\
ASW30 & $72.3 \pm 1.2 \mathrm{dc}$ & $84.5 \pm 2.2 \mathrm{a}$ \\
ASW60 & $79.0 \pm 0.6 \mathrm{a}$ & $85.6 \pm 1.6 \mathrm{a}$ \\
ASW90 & $73.0 \pm 0.4 \mathrm{bcd}$ & $84.3 \pm 2.8 \mathrm{a}$ \\
ASalc15 & $76.8 \pm 2.3 \mathrm{ab}$ & $87.9 \pm 3.1 \mathrm{a}$ \\
ASalc30 & $70.3 \pm 2.4 \mathrm{~d}$ & $77.0 \pm 4.4 \mathrm{ab}$ \\
ASalc60 & $66.0 \pm 3.3 \mathrm{e}$ & $72.7 \pm 8.9 \mathrm{~b}$ \\
ASalc90 & $76.5 \pm 2.2 \mathrm{ab}$ & $76.9 \pm 1.6 \mathrm{ab}$ \\
Vitamin $\mathrm{E}(200 \mu \mathrm{g} / \mathrm{mL})^{\mathrm{a}}$ & $77.1 \pm 1.3$ & $51.2 \pm 6.8$ \\
Vitamin C $(200 \mu \mathrm{g} / \mathrm{mL})^{\mathrm{a}}$ & $94.2 \pm 2.6$ & $0.0 \pm 0.0$ \\
\hline
\end{tabular}

ASW represents water extraction.

ASalc represents alcohol extraction.

Mean \pm SD $(n=3)$, mean within a column followed by the same lowercase letter are not significantly different at $p>0.01$

a Positive control.

However, the DPPH scavenging activity of the AS ethanol extract increased again when the extraction time extended to $90 \mathrm{~min}$. The AS extracts were also evaluated for their ability to reduce lipid peroxidation induced by the Fenton reaction. The water extracts showed only slight variation in lipid peroxidation inhibitory activities with $p>0.05$. ASalc extract of $15 \mathrm{~min}$ exhibited a higher inhibitory activity on lipid peroxidation. Similar to the DPPH scavenging activity, the 60 -min extraction with $20 \%$ ethanol also showed a relatively lower inhibitory activity on lipid peroxidation.

Hydroxyl radicals $(\bullet \mathrm{OH})$ generated by the Fenton reaction are known to cause DNA strand breaks to yield open circular DNA (relaxed circular DNA). Hydroxyl radical scavengers can protect DNA from strand breaks induced by hydroxyl radicals. The hydroxyl radical scavenger ability of AS extracts was evaluated. Super-coiled DNA migrated faster than relaxed open circular DNA on an agarose gel electrophoresis, and DNA strand breakage was induced in vitro in the presence of $\mathrm{H}_{2} \mathrm{O}_{2}$ and $\mathrm{Fe}^{2+}$ (lane 2, Fig. 3). DNA in the presence of $\mathrm{H}_{2} \mathrm{O}_{2}$ or $\mathrm{Fe}^{2+}$ alone did not show significant strand breakage (data not shown). Treatment of DNA with ferulic acid (Fig. 3, upper) or AS extracts (Fig. 3, lower) reduced the concentration of relaxed circular DNA. In addition, it appeared that the most protective effect came from ASalc15 (lane 7, Fig. 3, lower).

The results of antioxidant evaluations suggest that a short AS extraction time ( $15 \mathrm{~min}$ ) is enough to produce a product with favorable antioxidant effect. All hydroxyl radicals in this

$\begin{array}{lcccccccc}\mathrm{FA} & 0 & 0 & 0.5 & 1.0 & 3.0 & 10 & 20 & (\mu \mathrm{M}) \\ \mathbf{F e}^{2+} & - & + & + & + & + & + & + & (3 \mu \mathrm{M}) \\ \mathbf{H}_{2} \mathbf{O}_{2} & - & + & + & + & + & + & + & (85 \mathrm{mM}) \\ \text { Lane } & 1 & 2 & 3 & 4 & 5 & 6 & 7 & \end{array}$

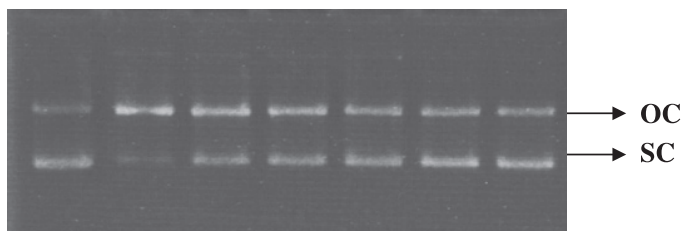

$\begin{array}{llllllllllll}\text { AS ext. } & \mathbf{0} & \mathbf{0} & \mathbf{2} & \mathbf{2} & \mathbf{2} & \mathbf{2} & \mathbf{2} & \mathbf{2} & \mathbf{2} & \mathbf{2} & (\mu \mathrm{l}) \\ \mathrm{Fe}^{2+} & - & + & + & + & + & + & + & + & + & + & (3 \mu \mathrm{M}) \\ \mathrm{H}_{2} \mathrm{O}_{2} & - & + & + & + & + & + & + & + & + & + & (85 \mathrm{mM}) \\ \text { Lane } & \mathbf{1} & \mathbf{2} & \mathbf{3} & \mathbf{4} & \mathbf{5} & \mathbf{6} & \mathbf{7} & \mathbf{8} & \mathbf{9} & \mathbf{1 0} & \end{array}$

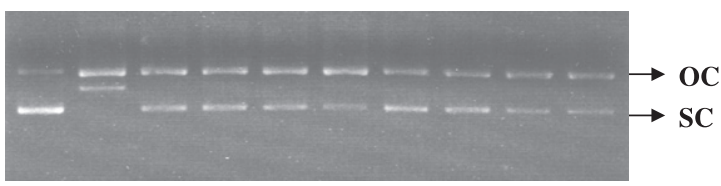

Fig. 3. Comparison of the AS extracts suppressed ROS induced DNA strand breakage. Upper: various ferulic acid (FA) concentrations (0.5-20 $\mu \mathrm{M})$; lower: AS extracts. SC, super-coiled form DNA; OC, open circular form DNA. Lane 1: only plasmid DNA, Lane 2: plasmid DNA with $\mathrm{H}_{2} \mathrm{O}_{2}$ and ferrous sulfate, Lane 3-10: plasmid DNA with $\mathrm{H}_{2} \mathrm{O}_{2}$, ferrous sulfate and AS extracts. Lane 3: ASW15, Lane 4: ASW30, Lane 5: ASW60, Lane 6: ASW90; Lane 7: ASalc15, Lane 8: ASalc30, Lane 9: ASalc60, Lane 10: ASalc90.

study were generated by Fenton reaction, which involved $\mathrm{Fe}^{2+}$ as radical initiator. The iron chelating ability of natural phytochemicals had been reported elsewhere to be an important criterion of antioxidation (Hagerman et al., 1998). This study further implies that the AS extracts enhance antioxidant activity through their iron chelating ability, in addition to being ROS scavengers.

\subsection{Inhibition of NO production by AS extracts}

The overproduction of NO is a key biochemical event during inflammation. Many anti-inflammatory agents possess effectiveness in suppressing NO production in vivo. In this study nitrite production was used as an indicator of NO released in the LPS-activated macrophage. The nitrite concentrations in culture 
A

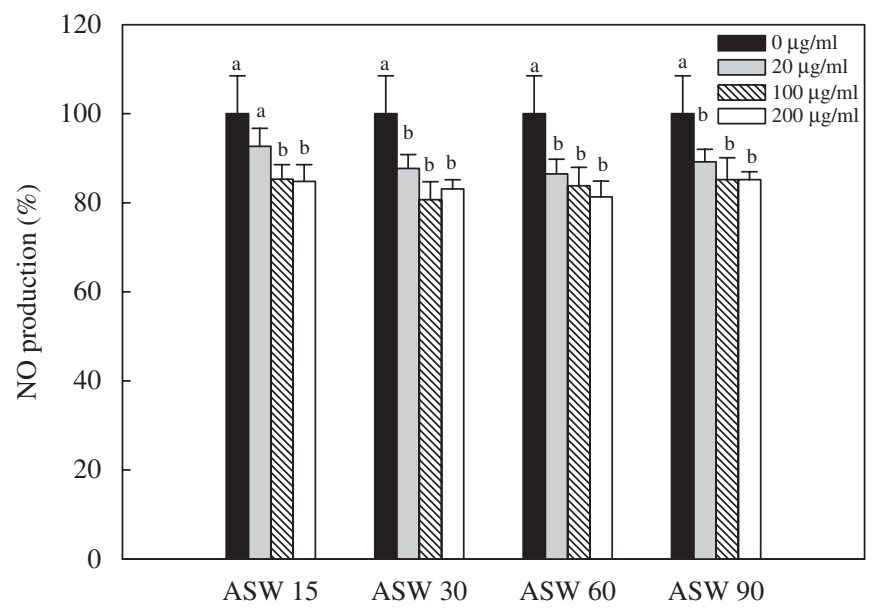

B

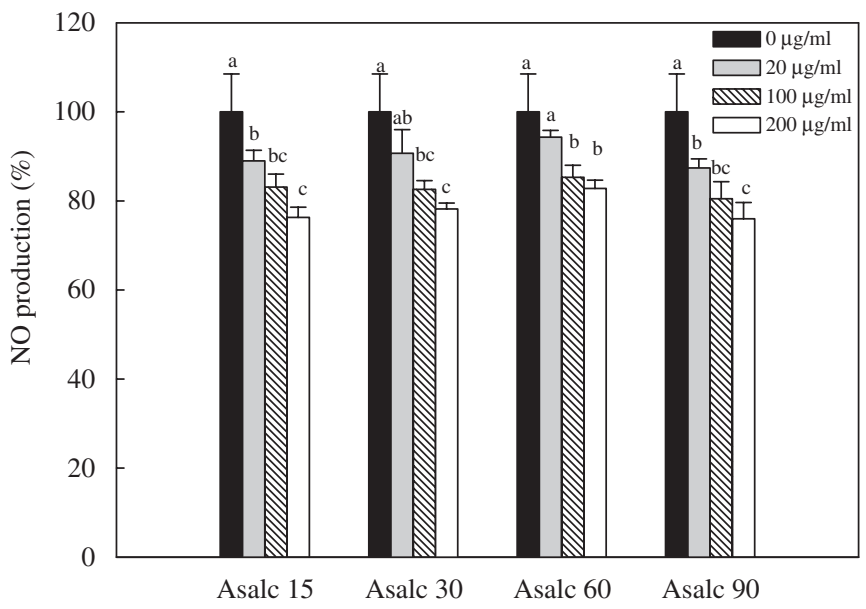

Fig. 4. Effect of AS extract on the NO production of Raw 264.7 cells in the presence of LPS. Raw 264.7 cells were cultured with AS extracts in the presence of $50 \mathrm{ng} / \mathrm{mL}$ LPS for $48 \mathrm{~h}$. Water extracts (A), alcohol extracts (B). The accumulation of NO was assayed by the Griess reaction. Data shown are mean \pm SD of the results of six cultures.

media were measured with and without AS extracts co-incubated macrophage activated with LPS $(50 \mathrm{ng} / \mathrm{mL})$. When LPS was administered to RAW 264.7 macrophages, the NO production increased dramatically. The AS extracts in the concentration range of $20-200 \mu \mathrm{g} / \mathrm{mL}$ showed inhibitory effects on NO production in LPS activated RAW 264.7 macrophage (Fig. 4). In general, the NO production decreased with increased extract concentrations. The results also suggested that a short AS extraction time ( $15 \mathrm{~min}$ ) was able to inhibit NO production in a dose-dependent manner at concentrations of 20,100 , and $200 \mu \mathrm{g} / \mathrm{mL}$ without cytotoxic effect (data not shown).

\subsection{Relationship between antioxidant activity and bioactive components of AS extracts}

The correlation coefficients between antioxidant activity and ferulic acid as well as TPA contents were calculated. It was found that the antioxidant activities (scavenging DPPH, inhibiting lipid peroxidation and NO production) were, in general, positively and linearly correlated with the ferulic acid and TPA for all extracts (Table 3 ). This result confirms that phenolic compounds in plant
Table 3

Relationship between antioxidant activity and various components in AS extract

\begin{tabular}{llll}
\hline Component & $\begin{array}{l}\text { Lipid } \\
\text { peroxidation, } r\end{array}$ & $\begin{array}{l}\text { DPPH } \\
\text { scavenging, } r\end{array}$ & $\begin{array}{l}\text { Inhibition of NO } \\
\text { generation, } r^{\text {a }}\end{array}$ \\
\hline $\begin{array}{l}\text { Water extract } \\
\text { Ferulic acid }\end{array}$ & 0.743 & & \\
TPA & 0.852 & 0.754 & 0.984 \\
Alcohol extract & & 0.789 & 0.918 \\
$\quad$ Ferulic acid & 0.923 & & \\
TPA & 0.896 & 0.890 & 0.898 \\
\hline
\end{tabular}

TPA: Total peaks area of phenolic acids.

a AS extract concentration was $200 \mu \mathrm{g} / \mathrm{mL}$.

food materials are the major contributors of their antioxidant activity, and $A$. sinensis is no exception.

\subsection{Flavor quality of AS extracts}

Heating the traditional Chinese medicine for a long time may cause compounds to decompose because some of them were found to be thermal labile (Song et al., 2004; Zhao et al., 2003). Long-term extraction at high temperature might also cause volatile aromatic oil evaporation (Doneanu and Anitescu, 1998), which might result in loss of the attractive special flavor of AS. The amounts of igustilide, butylidene phthalide, and butyl phthalide are the major volatile components of AS extracts (Kim et al., 2006a b), and they were chosen as the indication representatives of flavor property. A typical GC-MS chromatogram for the volatiles in AS is given in Fig. 5, and the changes of the contents of the major volatile components in AS extracts are shown in Fig. 6. The amounts of these compounds were much higher in $20 \%$ ethanol extracts than in boiling water. In the water extracts, the amounts of ligustilide $(1.28 \mathrm{mg} / 100 \mathrm{~mL}$, Fig. 6A) and butyl phthalide $(0.067 \mathrm{mg} / 100 \mathrm{~mL}$, Fig. $6 \mathrm{C})$ were the highest in the 60 -min extraction while butylidene phthalide $(0.082 \mathrm{mg} / 100 \mathrm{~mL}$, Fig. 6C) was highest in the 15 -min extraction. In the $20 \%$ ethanol extracts, the amount of ligustilide $(4.403 \mathrm{mg} / 100 \mathrm{~mL}$, Fig. $6 B$ ), butylidene phthalide $(0.187 \mathrm{mg} / 100 \mathrm{~mL})$ and butyl phthalide $(0.147 \mathrm{mg} / 100 \mathrm{~mL}$ ) (Fig. 6D) were higher in the 30 -min extraction than in other periods. The results indicate that $20 \%$ ethanol is better for extracting highly volatile aromatic oils than water. In the $20 \%$ ethanol extraction, more volatile compounds were obtained in $30 \mathrm{~min}$, and volatile compound content decreased once the extraction time exceeded that. This phenomenon was also found in water extraction processing except that the peak amounts of volatile compounds appeared in $60 \mathrm{~min}$.

Matsumoto et al. (1998) reported that ligustilide and butylidene phthalide reversed the decrease in pentobarbital sleep in isolated mice with induced stress, and concluded that these compounds contribute to the sedative action of Japanese angelica root (Angelica acutiloba KITAGAWA). Loss of volatile aromatic oil during processing not only reduced the flavor quality but also may decrease the health benefits of AS extracts.

In conclusion, this study has established a composition/ bioactivity change profile for AS under different extraction conditions, and suggests that extracting the AS with water or $20 \%$ ethanol for only $15 \mathrm{~min}$ can yield a product with the best antioxidant activity. With regard to the flavor quality, extraction of AS with $20 \%$ ethanol for 30 min yielded the highest amount of volatile oils. For obtaining a better flavor product with high antioxidant activity, we suggest that $20 \%$ ethanol should be used and the extraction time should be less than $30 \mathrm{~min}$. 


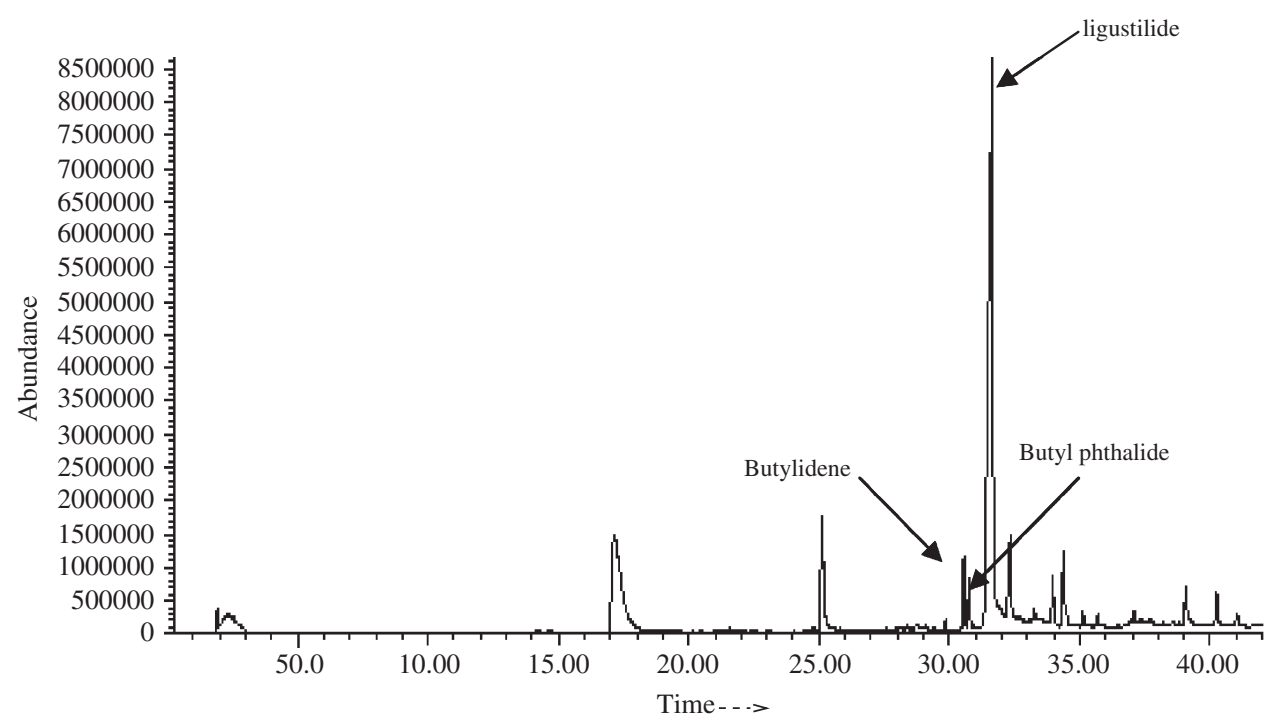

Fig. 5. Gas chromatography of volatile compounds of the Angelica sinensis extract. Using a Hewlett-Packard 5890 Series II chromatograph coupled to a Hewlett-Packard 5890A MSD mass spectrometer, and equipped with Carbowax $20 \mathrm{M}$ column $(30 \mathrm{~m} \times 0.32 \mathrm{~mm}$ i.d., film thickness $=0.25 \mu \mathrm{M})$ The injector temperature was $220^{\circ} \mathrm{C}$, detector temperature $260^{\circ} \mathrm{C}$, and the oven programmed from 50 to $220^{\circ} \mathrm{C}$ at an increasing rate of $5^{\circ} \mathrm{C} / \mathrm{min}$. The carrier gas was helium at a flux of $0.8 \mathrm{~mL} / \mathrm{min}$.

A
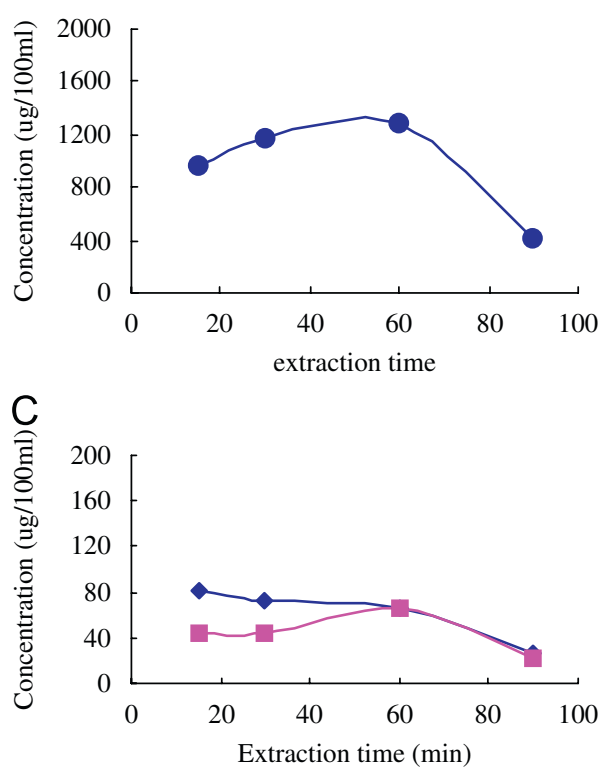

$B$
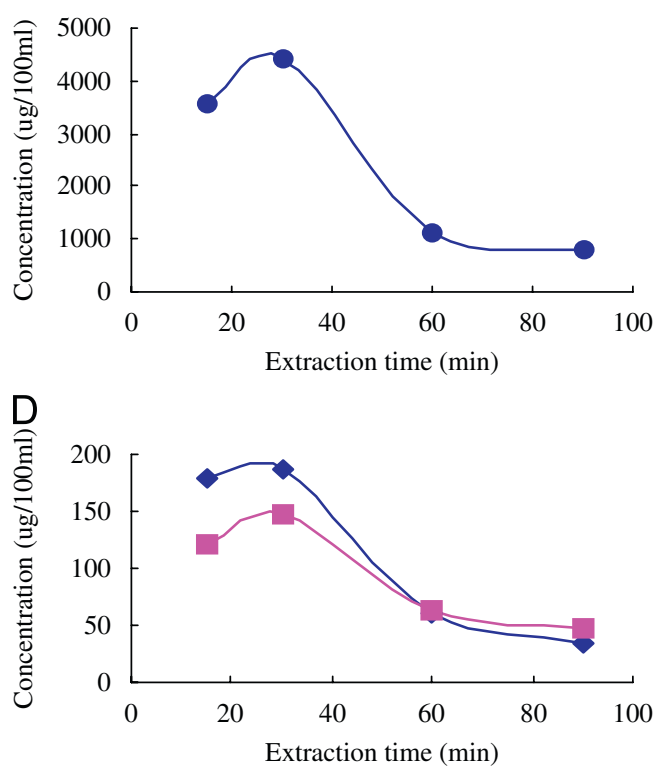

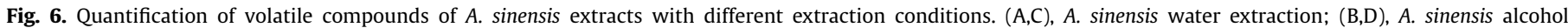
extraction.--, ligustilide; - -, butylidene phthalide; - $\mathbf{-}$-, butyl phthalide.

\section{Acknowledgment}

This study was supported by grants from the National Science Council (NSC 95-2214-E-002-004).

\section{References}

Cai, Y., Luo, Q., Sun, M., Corke, H., 2004. Antioxidant activity and phenolic compounds of 112 traditional Chinese medicinal plants associated with anticancer. Life Sciences 74, 2157-2184.

Charles, M., Martin, B., Ginies, C., Etievant, P., Coste, G., Guichard, E., 2000. Potent aroma compounds of two red wine vinegars. Journal of Agricultural and Food Chemistry 48, 70-77.

Chen, C., Tang, H.R., Sutcliffe, L.H., Belton, P.S., 2000. Green tea polyphenols react with 1,1-diphenyl-picrylhydrazyl free radicals in the bilayer of liposomes: direct evidence from electron spin resonance studies. Journal of Agricultural and Food Chemistry 48, 5710-5714.

Doneanu, C., Anitescu, G., 1998. Supercritical carbon dioxide extraction of Angelica archangelica Lroot oil. The Journal of Supercritical Fluids 12, 59-67.

Ermilov, A., Diamond, M.P., Sacco, A.G., Dozortsev, D.D., 1999. Culture media and their components differ in their ability to scavenge reactive oxygen species in the plasmid relaxation assay. Fertility and Sterility 72 (1), 154-157.

Gadow, A.V., Joubert, E., Hansmann, C.F., 1997. Effect of extraction time and additional heating on the antioxidant activity of Rooibos tea (Aspalathus linearis) extracts. Journal of Agricultural and Food Chemistry 45, 1370-1374.

Graf, E., 1992. Antioxidant potential of ferulic acid. Free Radical Biology and Medicine 13 (4), 435-448.

Hagerman, A.E., Riedl, K.M., Jones, G.A., Sovik, K.N., Ritchard, N.T., Hartzfeld, P.W. Richel, T.L., 1998. High molecular weight plant polyphenolics (tannins) as biological antioxidants. Journal of Agricultural and Food Chemistry 46, 1887-1892.

Hsu, H.Y., 1968. The Progress on Chinese Herbal Study. National Research Institute of Chinese Medicine, Taiwan, Republic of China. 
Hsu, H.-Y., Peacher, W.G., 1976. Chinese Herb Medicine and Therapy. Aurora Publishers Incorporated., Nashville, Tennessee, USA.

Huang, S.-T., Chen, C.-T., Chieng, K.-T., Huang, S-H., Chiang, B.-H., Wang, L.-F., Kuo, H.-S., Lin, C.-M., 2005. Inhibitory effects of a rice hull constituent on tumor necrosis factor $\alpha$, prostaglandin E2, and cyclooxygenase-2 production in lipopolysaccharide-activated mouse macrophages. Annals of the New York Academy of Science 1042, 387-395.

Huang, W-Y., Sheu, S-J., 2006. Separation and identification of the organic acids in Angelicae Radix and Ligustici Rhizoma by HPLC and CE. Journal of Separation Science 29 (17), 2616-2624.

Johar, D., Roth, J.C., Bay, G.H., Walker, J.N., Kroczak, T.J., Los, M., 2004. Inflammatory response, reactive oxygen species, programmed (necrotic-like and apoptotic) cell death and cancer. Annales Academiae Medicae Bialostocensis 49, 31-39.

Kanski, J., Aksenova, M., Stoyanova, A., Butterfield, D.A., 2002. Ferulic acid antioxidant protection against hydroxyl and peroxyl radical oxidation in synaptosomal and neuronal cell culture system in vitro: Structure-activity studies. The Journal of Nutritional Biochemistry 13, 273-281.

Khan, N.A., 2002. Antioxidants and cancer. The Sciences 2 (1), 38-43.

Kim, H., Lee, H.S., Chang, K.T., Ko, T.H., Baek, K.J., Kwon, N.S., 1995. Chloromethyl ketones block induction of nitric oxide synthase in murine macrophages by preventing activation of nuclear factor- $\kappa$ B. The Journal of Immunology 154, 4741-4748.

Kim, M.R., Abd El-Aty, A.M., Kim, I.S., Shim, J.H., 2006a. Determination of volatile flavor components in danggui cultivars by solvent free injection and hydrodistillation followed by gas chromatographic-mass spectrometric analysis. Journal of Chromatography A 1116, 259-264.

Kim, M.R., Abd El-Aty, A.M., Choi, J-H., Lee, K.B., Shim, J.H., 2006b. Identification of volatile components in Angelica species using supercritical- $\mathrm{CO}_{2}$ fluid extraction and solid phase microextraction coupled to gas chromatography-mass spectrometry. Biomedical Chromatography 20, 1267-1273.

Komatsu, W., Ishihara, K., Murata, M., Saito, H., Shinohara, K., 2003. Docosahexaenoic acid suppresses nitric oxide production and inducible nitric oxide synthase expression in interferon-gamma plus lipopolysaccharide-stimulated murine macrophages by inhibiting the oxidative stress. Free Radical Biology and Medicine 34, 1006-1016.

Lala, P.K., Chakraborty, C., 2001. Role of nitric oxide in carcinogenesis and tumour progression. The Lancet Oncology 2, 149-156.

Lander, H.M., Milbank, A.J., Tauras, J.M., Hajjar, D.P., Hempstead, B.L., Schwartz, G.D., Kraemer, R.T., Mirza, U.A., Chait, B.T., Burk, S.C., Quilliam, L.A., 1996. Redox regulation of cell signalling. Nature 381, 380-381.

Liu, S.-P., Dong, W.-G., Wu, D.-F., Luo, H.-S., Yu, J.-P., 2003. Protective effect of Angelica sinensis polysaccharide on experimental immunological colon injury in rats. World Journal of Gastroenterology 9 (12), 2786-2790.

Lu, G.-H., Chan, K., Chan, C.-L., Leung, K., Jiang, Z.-H., Zhao, Z.-Z., 2004. Quantification of ligustilides in the roots of Angelica sinensis and related umbelliferous medicinal plants by high-performance liquid chromatography and liquid chromatography-mass spectrometry. Journal of Chromatography A 1046, 101-107.

Lu, G.-H., Chan, K., Leung, K., Chan, C.-L., Zhao, Z.-Z., Jiang, Z.-H., 2005. Assay of free ferulic acid and total ferulic acid for quality assessment of Angelica sinensis. Journal of Chromatography A 1068, 209-219.

Manzocco, L., Anese, M., Nicoli, M.C., 1998. Antioxidant properties of tea extracts as affected by processing. Lebensmittel-Wissenschaft und-Technologie 31, 694-698.

Markesbery, W.R., 1997. Oxidative stress hypothesis in Alzheimer's disease. Free Radical Biology and Medicine 23, 134-147.

Matsumoto, K., Kohno, S.-I., Ojima, K., Tezuka, Y., Kadota, S., Watanabe, H., 1998. Effect of methylenechloride-soluble fraction of Japanese angelica root extract, ligustilide and butylidene-phthalide, on pentobarbital sleep in group-house and socially isolated mice. Life Sciences 62 (23), 2073-2082.

Ou, S., Kwok, K.-C., 2004. Review: ferulic acid: pharmaceutical functions, preparation and applications in foods. Journal of the Science of Food and Agriculture 84, 1261-1269.

Proestos, C., Sereli, D., Komaitis, M., 2006. Determination of phenolic compounds in aromatic plants by RP-HPLC and GC-MS. Food Chemistry 95, 44-52.

Sánchez-Moreno, C., Larrauri, J.A., Saura- Calixto, F., 1999. Free radical scavenging capacity and inhibition of lipid oxidation of wines, grape juices and related polyphenolic constituents. Food Research International 32, 407-412.

Song, Z.H., Ji, Z.N., Lo, C.K., Dong, T.T., Zhao, K.J., Li, O.T., Haines, C.J., Kung, S.D., Tsim, K.W., 2004. Chemical and biological assessment of a traditional Chinese herbal decoction prepared from Radix Astragali and Radix Angelicae sinensis: orthogonal array design to optimize the extraction of chemical constituents. Planta Medica 70 (12), 1222-1227.

Suzuki, Y.J., Forman, H.J., Sevanian, A., 1997. Oxidants as stimulators of signal transduction. Free Radical Biology and Medicine 22, 269-285.

Tse, H.M., Milton, M.J., Piganelli, J.D., 2004. Mechanistic analysis of the immunomodulatory effects of a catalytic antioxidant on antigen-presenting cells: implication for their use in targeting oxidation-reduction reactions in innate immunity. Free Radical Biology and Medicine 36, 233-247.

Varadarajan, S., Yatin, S., Aksenova, M., Butterfield, D.A., 2000. Review: Alzheimer's amyloid $\beta$-peptide-associated free radical oxidative stress and neurotoxicity. Journal of Structural Biology 130, 184-208.

Wu, D.Z., Song, C.Q., Hen, Z.F., Kong, J.L., Fan, Y., Hu, Z.B., 1999. Effects of Angelicae sinensis decoction for supplementing blood on the cardiac function in myocardial ischemia reperfusion injury of rats. Pharmacol. Clin. Chin. Mater. Med. 15, 3-6.

Yan, J.-J., Cho, J.-Y., Kim, H.-S., Kim, K.-L., Jung, J.-S., Huh, S.-O., Suh, H.-W., Kim, Y.-H., Song, D.-K., 2001. Protection against $\beta$-amyloid peptide toxicity in vivo with long-term administration of ferulic acid. British Journal of Pharmacology 133, 89-96.

Zhao, K.J., Dong, T.T.X., Tu, P.F., Song, Z.H., Lo, C.K., Tsim, K.W.K., 2003. Molecular genetic and chemical assessment of Radix Angelica (Danggui) in China. Journal of Agriculture and Food Chemistry 51, 2583-2786. 